\title{
The Value and Development Modes of Vernacular Aesthetic Education of Urban Agricultural Landscape
}

\author{
Hongya Tang* \\ School of Light Textile Engineering and Art, Anhui Agricultural university, Hefei 230036, Anhui Province, China \\ *Corresponding author: Hongya Tang, tangfinal2022@126.com \\ Copyright: () 2022 Author(s). This is an open-access article distributed under the terms of the Creative Commons Attribution License (CC \\ BY 4.0), permitting distribution and reproduction in any medium, provided the original work is cited.

\begin{abstract}
Aesthetic education not only exists in the classroom, but also in the urban living environment. The development of this environmental aesthetic education function is often accompanied by the development and change of urban landscape. Urban agricultural landscape is an organic part of modern urban landscape. It is different from machines or buildings in general urban production and life. Its local aesthetic value should be fully recognized and excavated. This is mainly reflected in the beauty of traditional agricultural skills, agricultural landscapes, and agricultural activities. At the same time, according to the different ways of interaction between people and the environment (ways of receiving aesthetic education), the development mode of vernacular aesthetic education of urban agricultural landscape can be divided into three: viewing mode, short-time contact, and long-time immersion.
\end{abstract}

Keywords: Urban agriculture; Vernacular aesthetic education; Value; Development mode; Local culture

Online publication: March 4, 2022

\section{Introduction}

Vernacular aesthetic education is an important channel for people to deeply understand the local culture and to be in contact with it. For a long time, vernacular aesthetic education has been regarded as one of the important contents of campus aesthetic education curriculum development by educational circles, but in fact, the significance, function, and scene of vernacular aesthetic education are not limited to this. Vernacular aesthetic education should be combined with other places and spaces outside the classroom, as well as flexibly influence and spread to the educated from multiple angles and forms. Urban public space is in fact an important aesthetic education scene for students studying in urban campus. Whether it is an urban landscape style or a public facility, the local cultural connotation reflected by it should undertake the aesthetic education media for urban people. On the other hand, urban agricultural landscape is an important aesthetic education resource in the interior or fringe of the city. Urban agriculture began to be a concern in the 1930s and has gradually matured after long-term development. Although domestic and foreign scholars are not completely unified in the conceptual discussion of urban agriculture, they believe that urban agriculture has positive significance for the sustainable development of both, urban and rural areas ${ }^{[1]}$. Urban agriculture has obvious social functions. It plays a profound role in spreading agricultural culture, increasing participants' knowledge, improving their sense of belonging, and enhancing social communication activities ${ }^{[1,2]}$. Therefore, this means that the excavation of vernacular aesthetic education value and the research on the development model of urban agriculture have strong practical demands. At 
present, the construction of urban landscape style in China has entered the stage of connotative development. The planning and development of local urban agriculture should be integrated into the shaping process of urban characteristic landscape, beginning from the local characteristics to combining the benefits of agricultural landscape with the functions of vernacular aesthetic education. Vernacular aesthetic education is not only restricted to the static knowledge content in textbooks, but also present itself as an opportunity for students to venture out of the campus and get in touch with good vernacular aesthetic education in the process of dynamic interaction and viewing of urban agricultural landscape. At the same time, vernacular aesthetic education can also exist as a broad and special spiritual demand of citizens. In order to meet this demand, urban agricultural landscape must promote the completion of various vernacular aesthetic education through a diversified "human environment" interactive development model.

\section{Vernacular aesthetic education value of urban agricultural landscape}

The purpose of vernacular aesthetic education is to enable students to enhance their feelings, understanding, and love for local beauty as well as form a systematic and clear cognitive system of local beauty. For local students, it is not only conducive to the cultivation of their aesthetic ability, but also to better understand their hometown and learn cultural knowledge or traditional skills with strong local characteristics ${ }^{[3,4]}$. Overall, urban agricultural landscape has a diversified vernacular aesthetic education value. In the process of value mining, it is not only important to consider the role of urban agricultural landscape in the dissemination of local history and culture as well as its involvement in urban landscape beautification, but also consider the significance of urban agricultural landscape in expanding educational space in urban life.

\subsection{Appreciate the beauty of traditional farming skills}

Urban agriculture contains various sightseeing or experiential agricultural activities, in which the agricultural production and life landscape that is notably different from the general urban landscape is formed. Due to the integration of agricultural resources with various extended functions, such as leisure, tourism, and sightseeing, the content of urban agriculture is not completely restricted to the narrow agricultural activities in traditional agriculture, but rather, related handicraft interactive experience activities may be included. Therefore, in the development of urban agriculture, considering the actual needs of tourism, sightseeing, leisure, research, science popularization, and so on, certain traditional skills closely related to agricultural activities can be selected. Public participation can also be heightened by improving and strengthening their presentation and operation forms. Especially for young people or students who are not familiar with traditional agricultural skills, they should go through relevant materials and process design to reduce the participation threshold of non-agricultural workers and enhance their interest, so as to reflect and give full play to the local aesthetic value of agricultural labor. The traditional skills involved in agricultural activities can be exposed to the aesthetic elements embedded in local agricultural traditional skills, which complement the local knowledge and aesthetic knowledge learned in textbooks. Through the project of experiencing traditional skills, students can gain a deeper understanding of the historical knowledge of agricultural production and life as well as experience the farming culture from plane image graphics and three-dimensional structures pertaining to agricultural tools involved in the skills. Local traditional skills reflect the concise skills and experiences formed in the long-term agricultural production and life process of the local people. Some local traditional skills are inseparable from the long-term agricultural life scenes, thus compelling the practical application of traditional skills to be functionally integrated into the external site landscape. In carefully planned and designed urban agricultural places and spaces, students can better appreciate the beauty of traditional farming skills and develop the aesthetic concept of local cultural spirit as well as local feelings by personally experiencing the process of farmingrelated skills. 


\subsection{Experience the beauty of agricultural scenery}

Urban agriculture allows citizens to experience the beautiful scenery formed by agricultural landscape, such as fishponds, farmlands, fruit trees, etc. For students studying in the city, the beautiful scenery composed of agricultural landscape can effectively make up for the urban landscape experience, comprising of modern infrastructures, and provide students the opportunity to experience the beauty of local land as well as to grow closer to the beautiful agricultural scenery. Crop landscape in urban agricultural landscape is different from the green belt of urban public space. On one hand, urban agricultural landscape is the spatial reflection of the characteristics of agricultural production and life. On the other hand, urban agricultural landscape is designed and planned, which is more exquisite in landscape style and diverse in function and scale. Therefore, compared with traditional agricultural landscape, urban agricultural landscape can be more aesthetically accepted by younger age groups in urban life. Students form direct feelings toward urban agricultural landscape through their visual sense. Therefore, the landscape style comprising of urban agricultural landscape is an important medium for younger age groups, including students, to accept vernacular aesthetic education. In the actual design and daily management of urban agricultural landscape, the local characteristics of crops must be considered. Therefore, it is reasonable to assume local crops as the source of urban agriculture. The scale and specific visual effects of urban agricultural landscape are different considering the actual situation. As the "second classroom" of vernacular aesthetic education, the expansion and implementation of vernacular aesthetic education function relevant to urban agricultural landscape have strong enforceability.

\subsection{Spreading the beauty of agricultural cultural activities}

In urban agricultural landscape, the elements of cultural activities derived from traditional farming activities can be displayed to reflect the local beauty. Cultural activities related to farming culture often have rich and diverse cultural and artistic forms. They are important channels for vernacular aesthetic education, such as dancing, sports, music, and so on. The origin and connotation of these cultural and artistic forms are often not enough to form direct and profound impact on urban young people or students living far away from farming life. Therefore, relevant management departments and professional designers should combine cultural activities related to farming scenes with the shaping of urban agricultural landscape, as well as survive in the process of urban agricultural tourism and sightseeing as high-quality vernacular aesthetic education. Cultural activities do not only contain the beauty of art, but also reflect the beauty of vernacular spirit and vernacular feelings behind history and traditional culture. However, many cultural activities rooted in agricultural activities are far from urban living areas and often have limited communication power for urban people. Therefore, it is necessary to superimpose and share the beauty of cultural activities with the help of urban agricultural landscape. Cultural activity scenes nested in urban agricultural space can be shared through the integration of traditional culture and place spirit, so that the audience can experience the vivid local beauty.

\section{Development modes of vernacular aesthetic education of urban agricultural landscape}

Urban agricultural landscape is not only a production landscape, but also a unique urban life landscape. In the process of functional orientation, planning and design, as well as resource development, it is necessary to focus on the functional expansion and embodiment of vernacular aesthetic education. In view of the different scales and forms of urban agricultural landscape, different development modes of vernacular aesthetic education can be explored. Based on the degree of interaction between people and landscape, this paper divides the development modes of vernacular aesthetic education into three types (Table 1). 
Table 1. Different characteristics of vernacular aesthetic education

\begin{tabular}{cccc}
\hline & Viewing mode & Short-term contact mode & Long-time immersion mode \\
\hline Medium & Vision & Participatory activities & Daily life \\
Function & Direct & Direct & Indirect \\
Object & Direct participant & Direct participant & People in daily life in the environment \\
\hline
\end{tabular}

\subsection{Development of vernacular aesthetic education function under the viewing mode}

Vision is an important sense for human beings to receive information about external things, and urban agricultural landscape is an ornamental medium that records the local "genes" in urban space. Urban agriculture concentrates and consolidates high-quality elements in traditional farming production and life by planting local crops and showing the local farming culture, so that people who view this urban agricultural landscape may develop a perceptual cognition of the beauty of local land. Therefore, urban agricultural landscape designed under the guidance of vernacular aesthetic education function must emphasis on the inheritance and innovation of landscape style. In terms of inheritance, the types of crops chosen must have local educational significance. The landscape formed by local crops should have an internal relationship with the traditional agricultural landscape, reflecting regionality and representativeness. In terms of innovation, it can be adjusted according to the audience and the spatial scale of the site. The spatial relationship should be adjusted under the limited spatial conditions, so as to better display the local beauty. This visual image of local beauty is between imitation and construction. It is a spatial embodiment of local aesthetic image. The visual image does not only express specific local farming elements, but also farming-related spirit and emotions, which are abstract and narrative. When people walk in the agricultural landscape space, they need to view each "image" from different perspectives to experience the beauty of local land. Therefore, landscape design needs to pay attention to the compound utilization of space, the appreciation of the front, middle, and back scenes, as well as the value of vernacular aesthetic education. The viewing of agricultural landscape should be combined with the surrounding urban elements, not deliberately avoiding the visual intervention of modern urban infrastructures and other elements, but effectively using modern elements to innovate or maintain the presentation of urban agricultural landscape. Through the differential presentation of urban agricultural landscape in different time periods, a variety of visual attractions in multiple time periods are formed, making it possible to experience the local beauty in different time periods.

\subsection{Development of vernacular aesthetic education function under the short-term contact mode}

The function of vernacular aesthetic education can be developed and expanded in the contact mode. Therefore, by increasing the short-term interaction between people and urban agriculture, people can better experience the beauty of local land. This short-term contact can be carried out through farming activities, which include both farming production activities and fun farming experiential activities. The activity scene of urban agriculture under the short-time contact mode is different from the original living space of the audience, such as agricultural park, roof farm, etc. ${ }^{[2]}$. Therefore, people who come for sightseeing or for the purpose of recreation and entertainment participate in various types of activity scenes, accompanied by curiosity and freshness. In the development of landscape resources, landscape designers should consider placing or integrating the link of interactive contact into the scene and enhance the educational scene of vernacular aesthetic education by adding a variety of interesting interactive facilities or activities. The probability of interactive people receiving vernacular aesthetic education is increasing. This educational scene can account for different spatial proportions in the overall landscape of urban agriculture, and the low interaction threshold can reflect the combination of teaching and fun. Due to the different scales of urban 
agricultural landscapes, a unified model for the frequency and duration of contact and interaction does not exist. The spatial carrier and environmental facilities of vernacular aesthetic education should be considered in line with the actual situation, and the characteristics of the audience should also be considered, including primary and secondary students in the "second classroom" teaching scene, children in the parent-child interaction scene, etc. For school students, due to their tight schoolwork time, the function of vernacular aesthetic education can be reflected through the short-time contact mode, so as to improve the efficiency of aesthetic education. Compared with the viewing mode, this mode focuses more on "interest" and has a more explicit embodiment of the educational purpose. It can be combined with the teaching design of "interest" as well as the planning and design of local landscape elements to boost the appeal of local beauty.

\subsection{Development of vernacular aesthetic education function under the long-time immersion mode}

The long-time immersion mode refers to the long interaction between people and urban agricultural landscape, which is multifaceted and long-term. Urban agricultural landscape can exist in people's daily lives and intersperse with other functional landscapes. Therefore, the vernacular aesthetic education function of urban agricultural landscape includes both explicit and implicit functions. For example, the paddy field campus of Shenyang Jianzhu University, where urban agricultural landscape and campus life landscape are combined. Students may also experience local beauty in the process of campus life ${ }^{[5]}$. Some urban agricultural landscapes are combined with urban greening. For example, local fruit trees do not only beautify the city as greening elements, but also allow the citizens to feel the beauty of local land ${ }^{[2]}$. This urban agricultural landscape combined with the living space landscape of ordinary citizens gradually plays its vernacular aesthetic education function under the long-term immersion mode. The functional development under this mode is accompanied by the imperceptible and immersive impact of the objective environment on the environmental population. It is necessary to pay attention to the coordination with other landscapes and prevent functional contradictions as well as spatial conflicts. At the same time, under this mode, the audience of vernacular aesthetic education is not limited to students, but ordinary citizens. Therefore, in the construction of such urban agricultural landscapes, it is important to pay attention to the combination of local beauty and the beauty of other life scenes.

\section{Conclusion}

The types and functions of urban agricultural landscape tend to be diversified at this stage of development. More and more people are paying attention to the functions and development modes of urban agricultural landscape from various perspectives. The vernacular aesthetic education function of urban agricultural landscape needs sustainable value development in order for it to be an important means of urban space as a vernacular aesthetic education place. Vernacular aesthetic education should not only exist in the classroom, but also widely combined with people's daily environment and space. The expression carrier of vernacular aesthetic education should be combined with the "locality" reflected in urban agricultural landscapes to carry out unified and sustainable functional development. This is to ensure that the influence of vernacular aesthetic education is not only on students or younger people, but also on other people. This paper holds that the urban style should not be homogenized in the development process, but rather, fully respect the local historical context and regional culture, which need to be fully reflected in the development of urban agricultural landscape. In the modernization of urban landscape, it is not only important to consider the actual needs of urban economic development, but also the spiritual impact of its urban space on people. The modernization of the city causes the original local land to cease to exist. Therefore, the development of the vernacular aesthetic education function of urban agricultural landscape is conducive to the continuation of urban culture; it can turn out to be an effective supplement to the vernacular aesthetic education classroom. 
In urban agricultural landscape design, in order to give full play to its vernacular aesthetic education value, it is important to consider the local construction of agriculture itself and choose an appropriate operation mode. There is a need to consider not only the objective environmental spatial order and proportional relationship, but also the spirit of the place. Vernacular aesthetic education is an aesthetic education based on local spirit. For urban youth who are far from the local life, the embodiment of local spirit should not only exist on campus or in the classroom but rather, fully combined with the construction of urban agricultural landscape to create a "second classroom." For ordinary people and families, vernacular aesthetic education can be implemented in the urban living environment and subtly play a positive role. Urban life and local beauty should not grow into a contradictory relationship. From the perspective of urban builders and managers, their future coexistence should be discussed. Just as some scholars have agreed on that there is a distinction between old and new local areas ${ }^{[6]}$, the author believes that the beauty of local areas does not only include the beauty of "old local areas," originating from traditional farming life, but also the beauty of "new local areas" with new technologies, new ideas, and new materials. The beauty of "new countryside" can be constructed actively and inherited innovatively. Therefore, the development of vernacular aesthetic education of urban agricultural landscape is essentially to seek the external manifestation of the beauty of "new countryside" along with relevant aesthetic education scenes and values. The development of urban agricultural landscape should consider its impact on people unfamiliar with agriculture and increase its cultural attraction to young people. Only when ordinary people are attracted by the beauty of urban agricultural landscape, can they experience the beauty of local land through agricultural landscape.

\section{Funding}

The 2021 Project of Aesthetics and Aesthetic Education Research Center of Sichuan Key Research Base of Social Sciences, "Study on the Development of Urban Agricultural Landscape Resources from the Perspective of Vernacular Aesthetic Education" (Project Number: 21C032).

\section{Disclosure statement}

The author declares no conflict of interest.

\section{References}

[1] Zhao JL, Chen YC, Mu WC, 2011, Review and Prospect of Urban Agriculture Study. Urban Development Studies, 18(10): 57-63.

[2] Jing XP, Zhou HY, 2015, Analysis on the Function and Realization of Urban Agricultural Landscape. Rural Economy and Science Technology, 26(01): 84-86.

[3] Li RH, 2021, Art Awakens the Countryside - New Thoughts on the Construction of Rural Aesthetic Education Curriculum. Art Education Research, 2021(10): 156-157.

[4] Long HX, 2014, The Present Situation and Significance of the Development of Local Aesthetic Education Curriculum Resources - A Case Study of Neijiang City, Sichuan Province. Journal of Liaoning Administration College, 16(05): 120-121, 123. DOI: 10.13945/j.cnki.jlac.2014.05.046

[5] Song TT, Xie R, 2021, Analysis of Landscape Design Under Maslow's Demand Level - Taking the Paddy Field Landscape of Shenyang Jianzhu University as an Example. Art Education Research, 2021(05): 64-65. 
[6] Yu KJ, Wang ZF, Huang GP, 2005, Discussion About the Vernacular Landscape and Their Implications to Modern Landscape Architecture. Huazhong Architecture, 2005(04): 123-126. DOI: 10.13942/j.cnki.hzjz.2005.04.039

\section{Publisher's note}

Bio-Byword Scientific Publishing remains neutral with regard to jurisdictional claims in published maps and institutional affiliations. 